Western University

Scholarship@Western

Education Publications

Education Faculty

2015

Embodied Experiences in Virtual Worlds Role-Play as a Conduit for Novice Teacher Identity Exploration: A Case Study

\author{
Anton Puvirajah \\ apuvirajah@gmail.com \\ Brendan Calandra \\ Georgia State University
}

Follow this and additional works at: https://ir.lib.uwo.ca/edupub

Part of the Education Commons

Citation of this paper:

Puvirajah, Anton and Calandra, Brendan, "Embodied Experiences in Virtual Worlds Role-Play as a Conduit for Novice Teacher Identity Exploration: A Case Study" (2015). Education Publications. 14.

https://ir.lib.uwo.ca/edupub/14 


\section{Embodied Experiences in Virtual Worlds Role- Play as a Conduit for Novice Teacher Identity Exploration: A Case Study}

Article in Identity · February 2015

DOI: $10.1080 / 15283488.2014 .989441$

CITATIONS

3

2 authors:

\section{Anton Puvirajah}

The University of Western Ontario

16 PUBLICATIONS 71 CITATIONS

SEE PROFILE
READS

61

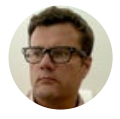

Brendan Calandra

Georgia State University

40 PUBLICATIONS 288 CITATIONS

SEE PROFILE

Some of the authors of this publication are also working on these related projects: 


$$
\frac{s^{4}}{b^{2}}
$$




\title{
Embodied Experiences in Virtual Worlds Role-Play as a Conduit for Novice Teacher Identity Exploration: A Case Study
}

\begin{abstract}
We present a descriptive case study of teacher-embodiment during a role-play parent-teacher conference in a collaborative virtual world. Using a single novice teacher as the primary unit of analysis, we describe the nature of teacher embodiment by deconstructing the teacher's various Discourses using Gee's Building Tasks as an analytical tool and reconstructing them using embodiment literature as a synthesis tool. Our findings indicate that well-designed experiences in collaborative virtual worlds coupled with meaningful reflection of those experiences have the potential to allow novice teachers to feel and act like a teacher, a phenomenon we call embodiment. The study provides theoretical and empirical basis for continued examination of the use of collaborative virtual worlds for clinical practice.
\end{abstract}

Keywords: embodiment, professional identity, collaborative virtual worlds, discourse analysis, designed experience
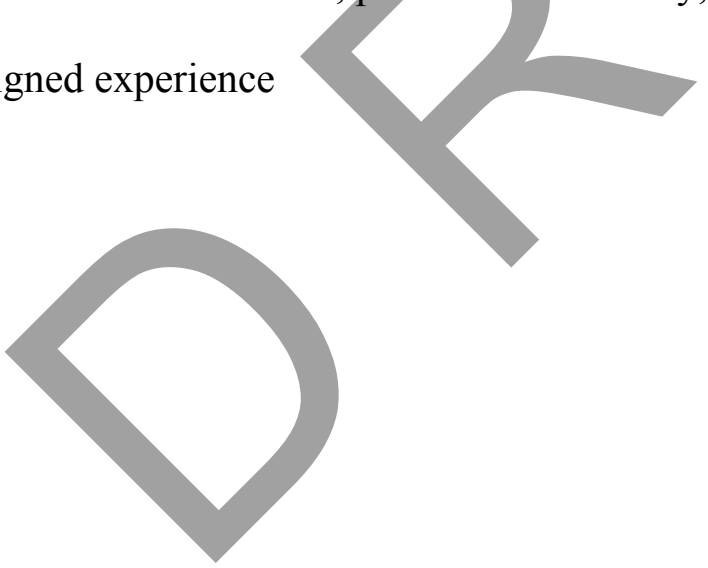


\section{Embodied Experiences in Virtual Worlds Role-Play as a Conduit for Novice Teacher Identity Exploration: A Case Study}

Novice teachers need multiple opportunities to practice being teachers. While courses focusing on beliefs, knowledge, orientations, and commitments related to the teaching profession are important, teacher education programs need to have greater focus on clinical practice (Ball \& Forzani, 2009). Deliberate inclusion of practice or pedagogy of enactment prepares novices to do the duties and activities of a teacher with more skill and with greater confidence when they enter the profession (Grossman, Hammerness, \& McDonald, 2009). If this kind of activity does not occur before a novice enters her first few years of teaching teacher quality, morale, and retention can adversely be affected.

In this article, we will briefly discuss the need for teacher education programs to have more deliberate focus on the actual tasks and activities associated with being a teacher and thus allowing novices to explore and possibly work toward committing to a teacher identity. We will stress that novice teachers need well-designed opportunities to try-out these tasks and activities if they are to bridge the gap between knowing and doing. We will also suggest that while it might be ideal, it is often infeasible to provide novice teachers with multiple and varied real-world opportunities to practice being a teacher. This is especially true when it comes to tasks such as managing classroom procedures and student behavior, and interacting with colleagues, administrators, and parents. Next, we will suggest that well-designed, nearauthentic experiences in three-dimensional collaborative virtual worlds along with meaningful reflection might be part of a potential solution. Finally, we will propose that evidence of the effectiveness and a desired outcome of these experiences is something we call teacherembodiment. In sum, what we present here is our case study examination and explanation of 
teacher embodiment during a role-play parent-teacher conference in a collaborative virtual world that occurred in our science teaching methods course.

\section{Background}

\section{Designed Learning Experiences}

As Kurt Squire (2006) put it, designed experiences involve "learning through a grammar of doing and being" (p. 19). In teacher education, one might conclude that designed experiences should provide novices with real or near-realistic practices in carrying out the tasks expected of a teaching professional. When we use the term designed experience, we mean purposefully and mindfully designed teaching experiences (Schneider, 2008). Designed experiences for novice teachers can take place in a variety of settings, ranging from roleplaying in traditional university classrooms to practice teaching in actual schools. Lampert (as cited in Ball \& Forzani, 2009) recommends a "continuum of settings, from virtual settings, to designed settings, or environments that are constructed for the explicit purpose of teaching practice, to actual settings, or real schools and classrooms in which novices can practice under entirely realistic conditions" (p. 504).

Although some may find it best to provide novice teachers with practice in real schools, logistical and ethical issues associated with practicing to teach among real children in an actual school limit these opportunities. Near-real experiences, however, can allow novice teachers to practice in lower stakes, safe-to-fail environments where there are opportunities to take risks and to be mentored by teacher educators (Luehmann, 2007). In addition, these types of settings can provide the teacher educator with the opportunity to concentrate on certain targeted aspects of the profession (e.g., classroom management or conducting parent-teacher conferences) without the distraction of other teacher activities, while at the same time lessen 
the novice teachers' cognitive load when learning within various complex domains of teaching (Hmelo-Silver, Duncan, \& Chinn, 2007).

\section{Embodied Practice}

We argue that practicing being a teacher leads to a sense of teacher-embodiment. This sense is a product of the coordination of mind-body-environment interactions. As such "bodily activity can have cognitive and epistemic meaning" as the body acts as mediator between the mind and environment (Anderson, 2003, p. 92). That is, the body plays an important role in providing "immediate and continuous information about our presence, activity, attention, availability, mood, status, location, identity, capabilities, and many other factors" (Benford, Bowers, Fahlen, Greenhalgh, \& Snowdon, 1995, p. 246). Thus, a bodily experience of the physical reality of a particular event or context enables us to gather, process, negotiate, and make sense of information that may not be available without the presence and the participation of the body (Dourish, 2004).

For example, can a young child learn to ride a bicycle without trying it? No matter how much and how well she may have read about it or observed other people riding bicycles, she will still need to have guided experiences in the physical reality of actually riding the bicycle before she can ride on her own. When she is practicing to ride, her body interacts with the environment (the bicycle and the surrounding), and then responds dynamically. In this dynamic response, there is real-time and bidirectional interaction between her mind, body, and the environment. This type of interaction is what we like to term embodied experience. The body is simultaneously embedded within the metaphysical mind and the physical world, and thus provides a conduit for phenomenological understanding of the environment. In phenomenological thought, experience leads to perception or understanding, rather than the 
reverse. "Embodiment [then] is an existential condition in which the body is the subjective source or intersubjective ground of experience," and as such looking into embodiment is "about culture and experience insofar as these can be understood from the standpoint of bodily being-in-the-world" (Csordas, 1999, p. 143). Accordingly, novice teachers' embodied experience is about being-in-the-world of a teacher and experiencing the cultural and discursive dimensions of being a teacher, rather than merely learning about the ideas of being a teacher. Lemke (2003) contends that embodied experiences are essential to our sense of self and for developing authentic accounts of identity. In this article we operationally define identity as either a role that is assumed by an individual or the recognition as a certain kind of individual that is manifested through Discourses to communicate either implicitly or explicitly the individual's sense of being, and includes goals, values, beliefs, and actions that guide the individual in "being" (Gee, 2000; Waterman et al., 2013).

\section{Embodiment through Designed Experiences in Virtual Worlds}

Novice teachers need multiple and varied opportunities to practice actually being a teacher, something that can provide them with a sense of teacher-embodiment. Issues associated with practicing in actual schools, however limit these opportunities. We propose that near-real experiences might allow novice teachers to practice in lower stakes, safe-to-fail environments where there are opportunities to take risks and to be mentored by teacher educators. One example of a tool that may assist in creating these types of embodied experiences is the collaborative virtual world. This is because collaborative virtual worlds can act as "model simulations to help us prepare for action in the world" (Gee, 2008, p. 256).

For the sake of this article, we will define collaborative virtual worlds as simulated three-dimensional graphical environments where real-world participants can represent 
themselves through online avatars and interact with various simulated artifacts, intelligent agents, and other avatars (Dede, Nelson, Ketelhut, Clarke, \& Bowman, 2004). While collaborative virtual worlds have their origins in the (video) gaming world as an entertainment medium, their once inferred educational affordances have been increasingly employed to provide targeted learning experiences (Shaffer, 2006). A number of collaborative virtual worlds exist that are deliberately designed to help learners master a skill, become knowledgeable about a phenomenon or topic, or experience a phenomenon (Harmon, 2011). It is well established in research literature that virtual world simulations can be used effectively and successfully to train individuals, often professionals, to refine an existing skill or to learn a new skill. For example, virtual worlds simulations have been used successfully for training surgeons on conducting minimally invasive surgeries (Gallagher, et al., 2013), undergraduate nursing students on postpartum hemorrhage management (Honey, Connor, Veltman, Bodily, \& Diener, 2012), commercial and military airline pilots (Aggarawal et al., 2006), and language learners (Peterson, 2011). Though affordances of using virtual world simulations for skills development are examined in various empirical studies and is summarized in a number of reviews, including Duncan, Miller, \& Jiang (2012), less established and less prevalent is the examination of the development of a deeper sense of being affiliated with a particular profession as a result of virtual world experience.

Literature has focused considerably on psychomotor skills development (learning to do) via virtual worlds; but the deeper cognitive aspects of virtual worlds experiences where there may be meaningful shifts in an individual's goals, values, beliefs, and actions that drive the individual in being (learning to be) have had less focus. While skills development or mastery of skills associated with a profession is important, of at least equal importance is 
learning to be or to become a member of a particular profession. An appropriately designed virtual worlds experience can offer both practices in skills associated with a particular profession and engagement with the cultural and social activities of the profession. This has the potential to allow for skills development and identity exploration and negotiation. That is, the situated nature of collaborative virtual worlds experience can play an important role in developing a sense of professional identity and belonging. Thus the learning that occurs is not just on how to do things, but is also "immersed within the culture or sets of practices one starts down the path of learning to be, engaging in the practices and absorbing the tacit knowledge that forms the cultural and social underpinnings of a community" (Thomas \& Brown, 2009, p. 40).

As learners participate in collaborative virtual worlds, they are not simply interacting with other occupiers of the virtual environment, but they are also creating or authoring themselves through their social interactions (Turkle, 1995). Collaborative virtual worlds experiences provide participants the opportunities to show and even explore certain aspects of their identities that they may not have had an opportunity to show and/or explore in the real world. In addition, these experiences can provide them opportunities to try other identities or amalgamate their identities with another. That is, as Turkle (1995) states "we come to see ourselves differently as we catch sight of our images in the mirror of the machine" (p.9). In a sense, participating in collaborative virtual worlds offers a different vantage point from which to examine our thoughts, intents, and actions.

Earlier we operationally defined embodied experience. We now suggest that embodied experiences can occur in a collaborative virtual world. Biocca (1997, p. 23) claimed that when participants are embodied in an avatar, two things occur: (a) The mental model of the user's 
body (body schema or body image) may be influenced by the mapping of the physical body to the geometry and topology of the virtual body; and (b) the virtual body may have different social meaning than the user's body, as the social meaning of the avatar is contextually dependent. Embodiment can be then thought of as the sense of presence felt by collaborative virtual world participants. Thus, the greater the feeling of presence, the greater the potential for embodiment experienced by the participants. Indeed, embodiment occurs as participants try to determine the capabilities of the body in the virtual space in order to determine who they are in that space (Clinton, 2004). For Biocaa (1997), embodiment occurs as the virtual body competes with the physical body to influence the mental representation of the body and persona that the body represents.

Within the context of teacher education, designed experiences in collaborative virtual worlds can augment other experiences in field placement courses and classroom-based methods courses. When the mind and the body of the avatar become the participants' surrogate mind and body, thus attributing certain mental and physical qualities to the avatar, in what Gee (2003) calls projective identities; and as novice teachers add their collaborative virtual worlds experiences to their real world methods class and field experiences, the line between the virtual and the real may blur. During this time, novice teachers might experience a certain kind of transformation that allows for the accommodation of these experiences (in virtual and real worlds) into their cognitive schema - a precursor for identity shift or commitment. In addition, these virtual spaces can be distributed across space and time, thus providing novice teachers with greater access to communities of practice where they can try out functional epistemologies related to being a teacher through their avatars (Squire, 2006). This is also supported through their interactions with other avatars in the virtual world. Such sociocultural 
contexts of the virtual world, just as in the real world, can have significant consequences on the exploration, formation, and commitment, of identities (Marcia, 1966; Taylor, 2002).

Unlike learning by being told, as in most methods classes - in virtual spaces, learning occurs by acting, trying and failing, and finding out through interactions that resemble realworld interactions (Gee, 2003). That is, novice teachers can embody themselyes in unfamiliar or less familiar roles. Role-playing in the virtual space then becomes an embodied experience through which novice teachers construct, deconstruct, and reconstruct an identity and a personality (a persona) of a teacher.

\section{Methodology}

Our approach to the study presented here is broadly based on the philosophical underpinnings of the (socio) constructivist paradigm, which assume that realities are constructed in the human mind based on interactions with others (social) and the environment (context) (Guba \& Lincoln, 1994). Thus within this paradigm, the assumption is that the contextual interactions between the researcher and the participant (object of the study) enable the creation of certain realities (research findings) that personify "the importance of subjective human creation of meaning, but doesn't reject outright some notion of objectivity" (Crabtree \& Miller, 1999, p. 10). More specifically, we present here a descriptive case study (Yin, 2009) of how one participant in a role-play parent-teacher conference in a collaborative virtual worlds projected teacher-embodiment. Since we wished to examine and describe the phenomenon of teacher embodiment, we chose to use a single novice teacher as our primary unit of analysis in order to provide a thick and holistic description of the phenomenon (Yin, 2009, p. 40).

\section{Context and Participant}


Our participant was a 24-year old Caucasian female student whom we will refer to as Joan Smith (a pseudonym). During the time of data collection, Joan was enrolled in the alternative preparation Master of Arts in Teaching (secondary science) program and was taking one of her first classes, a science methods course, in the program. The MAT program is intensive and takes, on average, about three to four semesters to complete. Students start taking their first two science teaching methods and other education and science content courses in the summer semester (first semester of the program). Joan entered the program with a bachelor's degree in biology and no prior teaching experience. As part of her methods course, she took part in lessons that included various discussions and activities related to classroom management. One of the culminating events of the classroom management unit was an assignment in which she had to participate (role-play) in a collaborative virtual worlds parentteacher conference. Joan played the role of the teacher (Ms. Smith) and a classmate played the role of the parent (whom we will refer to as Mr. Jones). The conference was carried out in the online virtual world Second Life, inside a simulation of a school building. The simulated school building and the spaces within it were designed to typify a real-world high school that our students in the teaching program would be placed for their clinical teaching experience. It is this role-play activity in the simulated space, and the ensuing reflection that we used to examine teacher embodiment.

\section{Data Collection}

First, we conducted a 90-minute workshop on the basic elements of using Second Life (the virtual world platform) and WeGame (screen recording software) for the students enrolled in the methods course. Students then formed groups of two or three. Each group was given a parent-teacher scenario (not a script) to role-play in the collaborative virtual world. All groups 
had the flexibility to determine who would play the parent(s) or the teacher. As the groups carried out their parent-teacher conferences in the collaborative virtual world, they were also asked to record their conference using WeGame. Students were then asked to watch the video recording, identify a critical incident in the video, and write a reflection on the incident using a critical incident reflection protocol as a guide (Calandra \& Brantley-Dias, 2010). Data sources for our study presented here were the video recordings of the virtual parent-teacher conferences and students' written reflections on the conference. We also transcribed the video of the parent-teacher conference.

\section{Data Analysis}

There were 12 parent-teacher role-play groups in the summer science teaching methods course. Of these, three groups were not considered for inclusion in the study, as there was least one member from each group who did not provide consent to participate. We made an initial pass through of the data from the remaining nine groups by viewing their videos and reading the transcripts and the reflections several times to determine the nature of the data collected as it related to our research objectives. Since the focus of our descriptive case study was to describe the phenomenon of teacher embodiment in the collaborative virtual world, we purposefully chose Joan Smith and her partner for our "intensive, holistic description, and analysis" due to the richness of the data set from which we felt we could learn the most (Merriam, 2009, p. x). The first author worked independently to inductively analyze the data using discourse analysis, and then corroborated the analysis with the second author, which fits the constructivist frame within which we were working. Our analysis of the data was guided by Gee's (2003) concepts of Discourse and Building Tasks. 
By Discourse (with a capital D), we mean an event where the meaning of words, phrases, and sentences are situated, or where the use and meaning of language is "customized to our actual contexts" (Gee, 2001, p. 716). For Gee, contexts are "not just the words, deeds, and things that surround our words or deeds but also our purposes, values, and intended course of action and interaction" (p. 716). Thus, in teaching, Discourse includes the situated language, the values, and the relationships that are characteristic elements of the teaching community or profession. Discourse can then be thought as something that allows us to "be things" and "take on socially significant identities" (Gee, 2011, p. 2). As such, Discourse allows teachers to be teachers and take on the identity of a teacher. When members of a community (e.g. teachers) speak, write, or use symbol systems or representations (i.e. taking part in Discourse), they are taking part in authoring a particular reality about themselves and the world around them (Puvirajah, Verma, \& Webb, 2012). Consequently, the essence of this study is to examine the type of reality that is being authored by Joan, our novice teacher, as she participated in a roleplay parent-teacher conference in a collaborative virtual world. Gee (2011) uses seven Building Tasks (activities associated with Discourse) to show how Discourse is used to construct human reality. Discourse is used to (a) create significance; (b) enact activities; (c) form relationships; (d) create, negotiate, and maintain identities; (e) affect the distribution of social goods (politics); (f) make connections among actions, words, or meanings to convey a message; and ( $\mathrm{g}$ ) privilege one type of knowing over another through the use of exclusive sign/systems and knowledge.

In our attempt to describe the nature of teacher embodiment, we deconstructed Joan's Discourses using Gee's (2011) Building Tasks as an analytical tool and reconstructed them using (teacher) embodiment as a synthesis tool. As in the real world, embodiment in the 
collaborative virtual world can be conjectured through various observations and analyses of

Discourse related to the event. That is, using Joan's recordings and written reflections we attempted to make certain assumptions about the extent to which her practice embodied that of teachers. We used the seven buildings tasks as a priori codes to identify how Joan's Discourses during the parent-teacher conference and during her reflection of the conference explored and built certain realities of being a teacher. Once the various Buildings Tasks were identified, we used the embodiment literature discussed earlier to examine the nature of Joan's teacher embodiment. Our analysis method is summarized below in Figure 1.

[Insert Figure 1 about here]

\section{Establishing Study/Analytical Quality}

We used Yin's (2009, p. 40) “case study tactics for four design tests ” as a guide to establish the quality of our study. Table 1 below provides a summary of how we did this.

[Insert Table 1 about here]

\section{Findings}

In this section we first present the findings of our analysis of Joan Smith's Discourses (non-verbal, verbal, written). Then, we use our findings to discuss teacher embodiment experienced by Joan Smith during her role-play parent-teacher conference in the collaborative virtual world. In the role-play, Ms. Joan Smith meets Mr. Jones, Suzanne's father in the school hallway and leads him to her classroom. There, they sit around a student desk and talk about Suzanne's performance in the class.

\section{Analysis of Joan Smith's Discourse Using Building Tasks}

The Discourses we undertake and the context in which these occur reflexively influence each other as we interact with people and things to create a certain reality for us 
(Puvirajah, Verma, \& Webb, 2012). For example when Ms. Smith interacts with Mr. Jones, she attempts to create Discourses that she thinks are appropriate for the context of the parentteacher conference. In turn, her Discourses also create or have impact on the context (Gee, 2011). Consequently, examining Ms. Smith's Discourses has the potential to reveal the type of reality she constructs within the parent-teacher conference context. Since Building Tasks are used by Ms. Smith to create this reality in her Discourses, we looked for the types of Building Tasks she was using. Before proceeding any further, it is appropriate now to present three types of Discourses that we analyzed. Ms. Smith's non-verbal Discourse (Figure 2) included her attire, gestures, actions, and interactions with people and things. Figure 2 presents a sequence of events where Ms. Smith waits for and then meets Mr. Jones in the school hallway, leads him to the classroom, offers him a seat, and sits adjacent to him. Ms. Smith's verbal Discourse was her parent-teacher conference talk ${ }^{1}$. Ms. Smith's written Discourse in form of her reflection of the parent-teacher conference is presented in the Appendix. Insert Figure 2 about here]

As we analyzed Ms. Smith's Discourses, we found that she attempted to create a certain teacher reality by using various Building Tasks. For example, our examination of her non-verbal Discourses revealed that her attire, actions, and interactions contributed to the authoring of her teacher persona. Similarly, Ms. Smith's dialogue with Mr. Jones during the parent-teacher conference, and the written reflection, also showed the use of Building Tasks to create that teacher persona. Summary of the various Discourse events and the associated Building Tasks are presented in Table 2 below. Close examination of Table 2 should reveal that a particular or similar Discourse event(s) could be used to show the enactment of multiple

\footnotetext{
${ }^{1}$ Complete transcript of the parent-teacher conference is available from the authors upon request.
} 
Building Tasks. For example, Ms. Smith's dress and her action of standing in the school hallway can show Building Tasks significance, activities, identities, relationships, politics etc. (see non-verbal Discourse column in Table 2).

[Insert Table 2 about here]

\section{Creating a Teacher Persona through Embodied Actions}

By teacher persona, we mean Discourses that try to emulate a typical teacher. As we noted in the previous section, Gee's Building Tasks were used to understand the type of teacher reality Ms. Smith was creating through her Discourse. She begins to create this teacher reality or teacher persona even before meeting with Mr. Jones. One of Ms. Smith's first actions in authoring her teacher persona is her creation of Ms. Smith, the teacher avatar. Even with the varied choices she had on Second Life, Ms. Smith created an avatar that looked and dressed much like a typical teacher. As seen in the above screen shots (Figure 2), Ms. Smith is professionally and appropriately attired for the parent-teacher conference; even though she had the flexibility to choose and dress her avatar in any way she wanted. We infer that Ms. Smith's creation of the avatar was consciously and deliberately made based on the context of her course assignment - that is, to role-play a teacher. The deliberate effort by Ms. Smith to create the avatar a certain way for the parent-teacher conference shows that she found meaning and value in the way she presents herself to others (we use the name Ms. Smith synonymously with the novice teacher and the avatar). That is, by dressing like a typical teacher, she is able to better exercise the rights, responsibilities, privileges, and other attributes of being a teacher.

In addition to her attire, Ms. Smith's interactions of the body with the environment also work to author her teacher persona. Namely, not only does Ms. Smith try to dress like a teacher, but also tries to physically act like one. We do not mean that her actions are unique to 
teachers, but our analysis reveal that her actions are consistent with teacher scripts and show sense of presence in the collaborative virtual world. In the sequence of events that appear in Figure 2, the first panel is Ms. Smith waiting in the school hallway for Mr. Jones to arrive. As opposed to being in the classroom, Ms. Smith finds it prudent to wait for Mr. Jones out in the hallway. This shows the importance she places on the parent-teacher conference. Waiting outside can indicate that Ms. Smith wants Mr. Jones to find her with ease, does not want Mr. Jones to waste time looking for her classroom, and wants to communicate a certain kind of eagerness and etiquette. Her action also has the possibility to let others know about the nature of the impending activity (waiting to meet somebody, possibly a parent). Seeing Ms. Smith outside the classroom also informs Mr. Jones about the possible nature of the impending activity and thus allows him to locate and identify his destination and his daughter's teacher. In her teacher role, Ms. Smith showed professionalism, courtesy, and forethought by waiting purposefully for Mr. Jones outside the classroom. By meeting him in the hallway (in the middle), as opposed to having him come to her classroom, Ms. Smith tries to establish some sort of symmetry in power in the relationship with Mr. Jones. The act of waiting outside also communicates the type of relationship (cordial, professional, and collaborative) that Ms. Smith would like to project to and have with Mr. Jones.

After they meet, Ms. Smith leads Mr. Jones into her classroom and directs him to sit in one of the student chairs. Here, Ms. Smith asserts her teacher role, shows power and authority as a teacher, and signals the type of relationship she wants to have with Mr. Jones by taking ownership of the activity and her physical space. After offering Mr. Jones a seat, Ms. Smith sits next to him. Her choice of sitting in one of the student chairs as opposed to sitting in the teacher chair creates the perception of symmetry in the distribution of power and mutual 
interest. In addition, the choice of seats and the relative position of the two individuals convey cooperation. Alternatively, if the seating arrangement was such that they were opposite to each other, it could convey competition, confrontation/defensiveness (Zweigenhaft, 1976). These non-verbal Discourses discussed above, contribute to the creation of a certain projected self which we contend largely resembled a teacher-self.

Ms. Smith begins the conference by discussing possible reasons for Suzanne's low performance on the latest biology test. She shares her concern for Suzanne's lower performance, ("Yes, I was really concerned about that too") and later in the same utterance asks Mr. Jones “Do you know why that might be?" These expressions align with what a typical teacher might say at the onset of a conference to present the issue and ask the parent for possible causes for the issue. This was also something that Ms. Smith learned from her science methods class. We discussed in class it was best to first ask parents empathetically for reasons about their child's sudden change in behavior and dispositions rather than for the teacher to tell the parents of possible reasons for the change. This becomes an invitation for the parents to share their concerns and observations about their child. In response to Ms. Smith's inquiry, Mr. Jones states that Suzanne does her school work at home and that she is a "straight A student in all her other classes." After five turns of conversation, finding that Mr. Jones was not able to help her find reasons for Suzanne's poor performance, Ms. Smith moves on to offer to help Suzanne with her biology course work by tutoring her after school, "I'll tell you what we can do; maybe she could stay after class with me. I will be more than happy to assist her after school and give her some one-on-one assistance too if that is okay with you." It is very possible here that Ms. Smith believes, that this is what teachers do - offer to help struggling students. We suggest that Ms. Smith creates her teacher script from what she has learned in her 
class and possibly from her experience with teachers and her notions of what teachers should be and should do. Although in class we discussed teachers should share the responsibility of student learning with the student, parents/caregivers, and other stakeholders, during the conference, Ms. Smith fails to communicate her expectations for Suzanne and how Suzanne's parents could help. In addition, Ms. Smith in at least seven rounds of the conversation in different ways tries to be overly accommodating to Mr. Jones.

Ms. Smith: ...I will be more than happy to assist her after school and give her some one-on-one assistance too if that is okay with you.;

Ms. Smith: Absolutely will, I'll call you or email you and let you know about her progress. I would be happy to do that.

For various reasons, including low professional confidence, perception of being overbearing, and feeling intimidated, novice teachers avoid conversations with parents where shared responsibility for the student's learning is discussed and negotiated. We find this relatively typical of novice teachers, and experiences like role-playing parent-teacher conferences in collaborative virtual worlds can help novice teachers confront and examine such practices.

While it seems Ms. Smith succumbed to novice teacher limitations by yielding some power to Mr. Jones as she became eager to help Suzanne and accommodate Mr. Jones' request for weekly progress reports, she nevertheless exerted authority over aspects of her teacher role. She maintained authority over her knowledge of Suzanne's performance, the appropriateness of the content and the test, and determining the proper recourse for Suzanne. Examining the conference Discourse revealed that Ms. Smith was knowledgeable about Suzanne's performance in the class and was able to provide specific details: 
Ms. Smith: In the beginning Suzanne was doing well but lately I have noticed that her grades have been falling as we progress through the class...;

Ms. Smith: ...Okay, well I have some documentation on me, for instance her last test. I see that she has a 60 on this...

When Mr. Jones suggested that the test might have been too difficult: Mr. Jones: ... she makes sure Suzanne is doing her work, so I don't understand why she's scored a 60? Do you think maybe the test may have been too hard?

Ms. Smith was able to defend the appropriateness of the test:

Ms. Smith: Well the average on the test itself was an 80 . So, that's actually a pretty good average to make in class and she was well below average.

Ms. Smith again showed authority over her teacher practices and choices:

Ms Smith: No it was an introduction to the class itself not specifically chemistry, an overview of everything they 've learned so far. She didn't grasp the basic concepts so, she is struggling now...

When Mr. Jones suggested that "chemistry aspect" of the test may have been a problem for Suzanne. Ms. Smith continued to exert her authority as teacher by recommending that Suzanne stay after class to get help.

Ms. Smith: I'll tell you what we can do; maybe she could stay after class with me... Just as Ms. Smith's non-verbal Discourses, her verbal Discourse also contributed to the authoring of a teacher. During the parent-teacher conference Ms. Smith expressed concern about the student (Suzanne), discussed and assessed her study routines and habits with the parent, and offered to support Suzanne with her biology course. These are relatively typical teacher conversation areas for addressing issues related poor performance. While we do not in 
any way imply that Ms. Smith role-played a flawless teacher, we point to her attempt at creating a teacher persona for herself using her best available knowledge about what teachers should do in similar situations. We feel that providing her the opportunity to role-play a teacher is one of the beginning steps toward exploring and then possibly committing to an identity of a teacher.

If role-playing is one of the beginning steps, then reflecting upon the role-play event becomes an important subsequent step in refining one's commitment to an identity through negotiation and consolidation, and generally making sense of the significance of the event. Ms. Smith does this in her written reflection (see Appendix). She carries out her reflection of the parent-teacher conference by analyzing her experiences, examining the various implications of her and Mr. Jones' actions, and planning for future practices.

In her reflection Ms. Smith analyzes her conversation with Mr. Jones regarding possible reasons for Suzanne's poor performance. In examining the implications of her actions, Ms. Smith acknowledges the she "was not able to exactly find the root of Suzanne's problem" and that instead "went right to a solution" because she says that she "was concerned about" her "student and therefore, did not want to put the blame on either Suzanne or her parents." An important revelation in Ms. Smith's reflection is the activity of planning for future action. Playing back the video and using the reflection form allowed Ms. Smith to critically examine her practices and learn from her experiences. As such, for future conferences, she intends to do the following:

I will try to find the root of the student's problem. I would try not to be afraid of asking some more personal questions, as long as the focus is always in the student and the parents or anybody else. I will make sure that the student is also there with the parents. 
I believe that sometimes it's good just to talk to the parents, but at other times, it is also good to include the student so that they can include their perspective and then perhaps we would have better understanding and a better solution as to how the student could be helped.

We find that refinement and enactment of certain teacher (professional) identity is revealed through Ms. Smith's written reflection. Reflective process allows one to take an (experienced) event and subject the event to critical analyses using various epistemologies (worldviews) and perspectives. When these analyses are both reflexively driven by and influence personal core beliefs, one's identity manifests itself in the process. We come to find out about Ms. Smith's emerging teacher identity as she tries to understand and learn from the events of the conference by examining these events through her existing worldview. For example, we find in her reflection that she finds it important to determine the reason for Suzanne's poor performance. Thus in this case, her emerging teacher identity is informed by her worldview of needing to find the cause of an issue before proposing an intervention.

We noticed in Ms. Smith's reflection the use of first person narrative to describe the role-play experience and the way she remained in her teacher role throughout the reflection. Ms. Smith stayed in character (of a teacher) as she examined, evaluated, and planned for future actions during her reflection process. She wrote her reflection in an authoritative yet introspective tone that showed evidence of an emerging teacher identity. We see through her Discourses, an alignment and identification with teachers. We infer that mindfully and purposefully designed experiences such as the role-play event and subsequent reflection have the potential to facilitate a shift of situated identity enacted by the participant toward a more robust form of identity where the participant increasingly begins to identify herself as a 
member of the social group that she role-played. The experiences that enabled Ms. Smith to identify herself as a teacher are what we like to call embodied experiences.

\section{Ms. Smith's Embodied Experiences}

In this study, we used two overarching constructs to show the extent to which novice teachers learn to take on the identity of a teacher in a collaborative virtual world. We used embodiment as a theoretical construct to frame our study, and we used Discourse as an analytical construct to help us unpack embodiment. Since embodiment is revealed through Discourse, these two constructs work well to complement each other in our study. We used Gee's Building Tasks as a priori codes, in order to highlight that Discourse allows us to be things and take on socially significant identities. We examined Ms. Smith's Discourses to determine the nature of teacher embodiment. We inferred that this could help with identifying the manifestation of a teacher identity. Thus we ask ourselves: How do Ms. Smith's Discourses align with the idea of embodied practice and more specifically teacher embodiment?

Analysis of Ms. Smith's data revealed her being-in-the-world of a teacher and experiencing the cultural and discursive dimensions of being a teacher - the essence of embodiment. Her professional attire, the way she waited for Mr. Jones in the hallway, the way she greeted and welcomed Mr. Jones, and her actions in enabling a seating arrangement that allowed for the perception of cooperative interaction, all highlight how she embodied the actions of a teacher. Teacher embodiment was also revealed through verbal and textual Discourses. During the conference, Ms. Smith discussed and offered some form of breakdown of Suzanne's grades, inquired into causes for Suzanne's low grades, encountered and tactfully dismissed parental suggestions of teacher malpractice, and led efforts to find ways for Suzanne 
to be successful. In her written reflections, Ms. Smith used a teacher lens to critically examine the events of her conference, provide rationale for her decisions and actions, and offer suggestions as to how she might do things differently next time. These actions are neither unique to teachers nor are they lone contributors to a teacher identity. However, we feel that these actions complemented together contributed to the totality of Ms. Smith's identity as teacher.

If the mind uses the body to make sense of what takes place around us, what happens when we populate an avatar (virtual manifestation of a body) in a collaborative virtual world? Let us say that novice teachers' embodied experience is about experiencing the cultural and discursive dimensions of being-in-the-world of a teacher; rather than simply studying about being a teacher. In that case, outside of actually being a teacher in a real school, projecting yourself onto a teacher avatar (virtual body) in a virtual school might be the next best thing. Indeed, this is certainly more authentic than discussing best practices or examples from texts, and it may be more authentic than role-play and/or microteaching in classrooms. This could be due to embodiment - embodiment afforded by the designed virtual experience. Using some of Wilson's (2002) claims we might say that Ms. Smith's collaborative virtual world experience is more likely to be embodied because it is situated in a closer to authentic context than that provided in a teacher education classroom. We would like to add that designed collaborative virtual worlds experience allows participants to detach themselves from their (real life) roles as students in a teacher education program. It allows them through a particular relationship with their avatar to form what Gee (2003) called a "projective identity" or learner as teacher (p. 65). This sense was evidenced throughout Ms. Smith's reflections that read as though she had participated in an actual parent-teacher conference. 
While Ms. Smith's Discourses occurred in the collaborative virtual world, her virtual body and the mental image of her body in the physical world seemed to be reflexively influenced by each other. For instance, we ascertained that the way Ms. Smith's avatar interacted with (not merely acted on) Mr. Jones, the virtual schoolhouse, and objects in the schoolhouse was guided to a certain degree by a more uninhibited mental image of her projected body and social interactions. This is based on the premise that most of us tend to hold mental images of our social interactions and our bodies that, for various reasons, do not completely become manifested in the real world. The designed collaborative virtual world experience thus may have allowed Ms. Smith to work with and develop mental images of herself and her social interactions that combined the virtual and the real. In other words, when mental images of the body and social interactions are acted out and developed in collaborative virtual worlds, there is greater potential for these developed mental images to become part of the real world Discourse - what we have called embodiment or embodied practice.

\section{Discussion}

Our focus on teacher embodiment in this article is grounded on the premise that the interaction of the mind, body, and the environment within realistic or near-realistic (realistically-simulated) conditions may allow for experiencing the cultural and discursive dimensions of being a teacher. We presented our case for how this may have occurred with Ms. Smith. Central to Ms. Smith's teacher embodiment was the deliberate inclusion of pedagogies of enactment in her summer methods course that focused on trying out and reflecting on core teacher practices. That is, we provided our novice teachers with designed experiences in being a teacher and opportunities to critically examine their experiences with the expectation that these experiences will act to promote an increasingly committed teacher identity in them. Our 
intent in doing this, as highlighted earlier, is to prepare novice teachers who are better able to handle the realities of teaching by incorporating and making use of the knowledge that they acquired during their teacher preparation in their professional practice (Grossman, Hammerness, \& McDonald, 2009). While most teacher preparation programs, including ours, focus on numerous core practices of teaching, melding the philosophical and the theoretical within a social justice framework, little by way of application of the learned knowledge occurs. Just as Korthagen \& Kessels (1999) contend, too often it is left for the novice teachers to make sense of and apply what is learned to their teaching practice. However by the time they attempt for the first time to apply to their classroom what was learned in their preparation programs, the stakes for failing become high. By providing novice teachers with multiple opportunities to enact core teacher practices and then reflect on their enactments in teacher preparation programs we can increase the likelihood of them performing more skillfully and with greater confidence when the stakes are high. We could say, similar to what occurred with Ms. Smith, designed experiences in being a teacher allows participants to explore teacher identity, and then possibly gauge and examine their level of commitment to that identity earlier and within a safe-to-fail environment.

collaborative virtual worlds, we briefly discuss three affordances of the collaborative virtual world experience that allowed our teachers and more specifically Ms. Smith begin to develop her teacher identity. These are (a) self-creation and control of the avatar (b) sense of presence and co-presence felt, and (c) critical reflection of the experience. In our study, Ms. Smith created a teacher avatar. The process of imagining, visualizing, and trying out and retrying involved in the creation of the teacher avatar allows for and enables the novice teacher to 
begin to have embodied experiences related to being a teacher. As Pena, McGlone, \& Sanchez (2012) reported in their study, experiences in creating and controlling a teacher avatar may allow users to subconsciously act like teachers because of the contextualized and situated nature of the experience.

The second set of affordances of the collaborative virtual world experience that we noticed during our analysis, that are also cited in research literature (Choi \& Baek, 2011; Dalgarno \& Lee, 2010), were the sense of presence and social presence (co-presence) felt by Ms. Smith and others. A sense of presence is an inner feeling that you are really there, while a sense of social presence describes the feeling of both being there and also sharing sensorial experiences with others (Bulu, 2012). The two combined states make it possible for participants to feel as if the virtual world is real (Jelfs \& Whitelock, 2000). In addition, because virtual worlds can be distributed across space and time, they can provide greater access to teacher learning communities across geographically dispersed locations where members learn about teaching by collaboratively doing the things that teachers do via their avatars (Hew \& Cheung, 2010; Muir, Allen, Rayner, \& Cleland, 2013). Sociocultural contexts such learning communities, just as in the physical world, can have significant consequences on the formation of (teacher) identities (Lave \& Wenger, 1991; Taylor, 2002). This may be the case because as learners participate collaboratively in virtual worlds, they are not merely interacting with others in the virtual environment; they are also creating or authoring themselves through avatars and their social interactions (Turkle, 1995). Thus, we emphasize that having both the sense of presence and sense of co-presence facilitates more meaningful and authentic gathering, processing, negotiating, and making sense of information that may not be available without the presence and the participation of the (virtual) body. 
An essential component and the third affordance of the overall designed experience was the required reflective writing experience that was guided by the examination of the video recording of parent-teacher conference. The reflective writing experience allowed the novice teachers, including Ms. Smith, to relive, critically examine, and consolidate their collaborative virtual world parent teacher conference experiences, and plan for similar scenarios in the future. Thus these processes involved in reflection worked to support the formation of a more stable and schematized cognitive structures of the virtual parent-teacher experience and what it entails to be a teacher. Consider for example an episode in which novice teachers participate in a collaborative virtual world parent-teacher conference without the reflection component. Since novice teachers are not given a formal and deliberate opportunity, by way of reflection, to integrate their parent-teacher conference experiences with their existing cognitive structures (schema), their experiences become rather incomplete and ineffective in helping to develop any kind of teacher identity. As such we emphasize here that while the collaborative virtual world provides a means to experience near authentic teacher practices, meaningful reflection of these experiences is essential for developing substantive and long lasting ideas and skills about teaching (Schon, 1987). Ms. Smith for example continued to author herself as a teacher during the reflective writing process and this enabled her to develop certain notions about her just experienced practice, and think about and plan for future practice. We can think of the reflection portion of the designed experience as being similar to and essential as the requirement of sleep for the consolidation of various types of experiences and memories (Stickgold, 2011).

While reflection was emphasized in the previous paragraph, we also note that experiences in the collaborative virtual world provide the situation for reflection. The tandem 
effect of the collaborative virtual world experience and the subsequent reflection enables participants to shift their identities associated with teachers and teaching from that of a 'novel' situated identity to their more stable core identity (Gee, 2001). What we mean is that, when novice teachers participate in the collaborative virtual world parent-teacher conference - a situation that is relatively new to them - their participation is primarily guided by a combination of their emerging and largely untested notions of what ought to happen during a parent-teacher conference and what is the most socially appropriate response to the situation. Situated identity theory posits that novice teachers who are put into this situation, to make sense of and to respond to it, try to define the situation, assume or construct certain social reality about the situation, and choose among various alternatives before acting (Alexander \& Lauderadale, 1977). Thus we say that situated identity is an identity assumed or enacted by an individual for a finite duration of time for the purpose of accomplishing a task within a specific context. However, enactment of situated identity may or may not be facilitated by one's core identity. This largely depends on the familiarity of the task and the personal value of the task. The intent of the designed experience then is to help novice teachers become more familiar with the task of teaching and to nurture a sense of personal value to this task. We want our novice teachers to move from mere technical decision-making about teaching to developing certain core philosophies and beliefs about teaching that drive their teacher-related decision-making process. When this happens, there is greater likelihood that these teacher philosophies and beliefs will become an integral part of their core identity. Thus in our study the reflective writing component of the designed experience worked to negotiate, consolidate, and transform the technical aspects of the teacher practice enacted by the novice teacher in the collaborative virtual world to an entity that is internalized proximal to one's core identity, 
allowing for a more complete embodied experience in being a teacher. While embodied practice begins to occur as soon as Ms. Smith enacts her situated identity to create her teacher avatar at the beginning of the collaborative virtual world experience and remains throughout the entire designed experience, her embodied reflective practice (Kinsella, 2007) aided in the movement and/or negotiation of her teacher identity toward her core identity.

While we have described the collaborative virtual world experience and the ensuing reflection as supporting a possible shift from situated identity toward core identity, similarly it is also possible to frame the entirety of the experience as a moye from identity exploration to a more committed identity (Marcia, 1966). That is, the designed experiences allow novices to explore teacher identity and exhibit the commitment to that identity through their Discourses. Thus the extent or degree of commitment can be associated with the proximity of the teacher identity to core identity where a more stable set of "specific set of goals, values, and belief that provide a sense of direction" in life resides (Waterman et al, 2013, p. 2).

We now turn to briefly discussing why we feel that collaborative virtual world augments real-world experiences to provide embodied experiences. Virtual worlds experiences, when designed appropriately, can help novices to scaffold learning and experiences in a place that is safe to try, take risk, fail, and try again. In essence, collaborative virtual world experiences can be considered as a stepping-stone to real life training and practice experiences, where risks are greater and resources are limited. Virtual worlds also enable easier access to practice opportunities because practice can occur from anywhere and at any time where there is computer and Internet access. Virtual worlds participation can also be 'anonymized' so that users feel more at ease to try out Discourses that they would not try in the real world. Virtual world experiences provide participants the opportunities to show and even explore certain 
aspects of their identities that they may not have had an opportunity to show and/or explore in the real world. In addition, these experiences can provide participants opportunities to try other identities or integrate their identities with another. As opposed to university-based role-play experiences, which can be limited by time, space, and other resources, virtual worlds role-play affords greater flexibility in time, space, and resources. In well-designed virtual worlds, experiences can be simulated to be near realistic. In addition, the sense of embodiment one feels in near-real virtual environments because of the sense of presence and co-presence one feels is difficult to have in university-based classrooms.

We (Calandra \& Puvirajah, 2014) describe four practice spaces for novices based on the degree of interaction of the mind, body, and environment. In the first space, the mind is the sole entity involved in learning. Reading, listening to a lecture, watching a video are all examples of only the mind being involved in learning. Learning occurs through information provided by others and thus the authenticity of the experiences, the relevance of the experiences for learning, and the cognitive and sensory load for learning are low. In the second space, the mind and the body are involved in learning. Microteaching practices and role-plays are examples of this. Learning occurs through doing. However, because of the largely decontextualized nature of these practices, the authenticity of the experiences, the relevance of the experiences, and cognitive and sensory load for learning are low. In the third space, the body and the environment are involved in learning. Premature practice experiences in real world environments, such as classrooms are examples of this. Learning occurs through being in the environment. While the authenticity of the experiences is high, the relevance of the experiences for learning is lower because cognitive and sensory load of the experience maybe too high, resulting in instinctual acquisition of knowledge. In the fourth space, mind, body and 
the environment are involved in learning. Experiences in well-designed virtual spaces are an example of this. Learning occurs through being. While the authenticity of the experiences is medium to high, the relevance of the experiences for learning is high because of the appropriate and scaffolded cognitive and sensory load of the experiences. Fourth space experiences allow for personally constructed and professionally meaningful knowledge to be acquired through embodied reflective practices.

\section{Summary and Conclusion}

Affordances of using virtual worlds simulations as a training ground for real life situations are documented in various research literatures. Some examples where virtual worlds and virtual simulations are used for training include: military and soldier training, simulations of flight and other transport devices, war games, medical surgeries, bedside manners of health professionals, educational and educative games, teacher and other practitioner training, clinical counseling simulations, telehealth etc. With ever increasing advances in computing and other associated technologies, the use and incorporation of virtual simulations in many aspects of training, therapy, entertainment, and communication are only going to grow. However, there is limited research on the impact and affordances of virtual worlds participation on identity exploration, negotiation, and development. The presented study is our first attempt at developing a theoretical frame to examine identity exploration and negotiation in virtual spaces. As such, we had three foci for our study (a) to present a theoretical frame (embodiment, embodied cognition, situated identity) to study the nature of virtual worlds participation for various outcomes; including identity exploration, identity negotiation, identity development at the core level and various skills development at the peripheral level, (b) to present Discourse analysis and Gee's Building Tasks as a methodological approach to examine virtual world 
interactions, and (c) use the presented theoretical and methodological frames to study the nature of virtual world participation. Thus, while the context our study is preservice teacher training, we feel that our theoretical and methodological framework could be used in a variety of virtual worlds contexts where there would be interactions among avatars, objects, and environment.

Our intent here was to demonstrate that well-designed experiences in collaborative virtual worlds have the potential to allow novice teachers to feel and act like a teacher (embodiment). We used video recordings of participants' role-play activities and participants' written reflections on those activities as data. And we used Gee's (2011) concept of Discourse as our framework for data analysis with the concept of embodiment as our anticipated outcome. While we cannot claim to know the extent to which teacher actions and mannerisms in the virtual or real world are deliberate, our focus here was on deconstructing teacher actions and mannerisms in order to understand the function of various teacher Discourses on teachers' embodied practices. As our current study is largely interpretive, we hope it can provide a way for researchers, teacher educators, and teachers to continue to examine the use of collaborative virtual worlds for clinical practice - especially in programs where, due to time and other logistical constraints, actual practice (teaching) is not feasible. While we do not advocate or propose to supplant real-world practice teaching experiences, we do suggest that welldesigned experiences in collaborative virtual worlds can be used successfully when the other is unavailable or infeasible or as an intermediary step prior to real-world practice. Well-designed collaborative virtual worlds experiences might offer an accessible and safe-to-try-and-fail platform for learners. Let us think back to the bicycle analogy. In both cases (learning to ride a bicycle and learning to be a teacher), it is a good idea to provide actual practice, but likely not 


$$
0^{p^{R^{r^{k}}}}
$$




\section{References}

Aggarwal, R., Tully, A., Grantcharov, T., Larsen, C. R., Miskry, T., Farthing, A., \& Darzi, A. (2006). Virtual reality simulation training can improve technical skills during laparoscopic salpingectomy for ectopic pregnancy. BJOG: An International Journal of Obstetrics \& Gynaecology, 113, 1382-1387.

Alexander Jr, C. N., \& Lauderdale, P. (1977). Situated identities and social influence. Sociometry, 40, 225-233.

Anderson, M. (2003). Embodied cognition: A field guide. Artificial intelligence, 149, 91-130.

Ball, D. L., \& Forzani, F. M. (2009). The work of teaching and the challenge for teacher education. Journal of Teacher Education, 60, 497-511.

Barker, L. (2008). Unpacking what people are doing with D/discourse with Gee's framework Retrieved 1 August, 2012, from http://courses.ischool.utexas.edu/Barker_Lecia/2008/fall/INF385N/resources.php

Benford, S., Bowers, J., Fahlen, L. E., Greenhalgh, C., \& Snowdon, D. (1995, May). User embodiment in collaborative virtual environments. The proceedings of the SIGCHI conference on human factors in computing systems (pp. 242-249). ACM Press/Addison-Wesley.

Biocca, F. (1997, August). The cyborg's dilemma: Embodiment in virtual environments. Article presented at the Second Cognitive Technology Conference, Aizu, Japan.

Bulu, S. T. (2012). Place presence, social presence, co-presence, and satisfaction in virtual worlds. Computers \& Education, 58, 154-161. 
Calandra, B., \& Brantley-Dias, L. (2010). Using digital video editing to shape novice teachers: A generative process for nurturing professional growth. Educational Technology, 50, $13-17$.

Calandra, B \& Puvirajah, A. (2014). Teacher practice in Multi User Virtual Environments: A fourth space. Tech Trends. 58, 29-35.

Clinton, K. (2004, April). Embodiment in digital worlds: What being a videogame player has to teach us about learning. Paper presented at the American Educational Research Association, San Diego, CA.

Choi, B., \& Baek, Y. (2011). Exploring factors of media characteristic influencing flow in learning through virtual worlds. Computers \& Education, 57, 2382-2394.

Crabtree, B. F., \& Miller, W. L. (1999). Doing qualitative research. Thousand Oaks, CA: Sage Csordas, T. J. (1999). Embodiment and cultral phenomenology. In G. Weiss \& H. F. Haber (Eds.), Perspectives on embodiment: The intersections of nature and culture (pp. 143164). New York, NY: Routledge.

Dalgarno, B., \& Lee, M. J. (2010). What are the learning affordances of 3-D virtual environments? British Journal of Educational Technology, 41, 10-32.

Dede, C,, Nelson, B., Ketelhut, D. J., Clarke, J., \& Bowman, C. (2004). Design-based research strategies for studying situated learning in a multi-user virtual environment. In Proceedings of the 6th International Conference on Learning Sciences (pp. 158-165). International Society of the Learning Sciences.

Dourish, P. (2004). Where the action is: the foundations of embodied interaction. Cambridge, MA: The MIT Press. 
Duncan, I., Miller, A., \& Jiang, S. (2012). A taxonomy of virtual worlds usage in education. British Journal of Educational Technology, 43, 949-964.

Gallagher, A. G., Seymour, N. E., Jordan-Black, J. A., Bunting, B. P., McGlade, K., \& Satava, R. M. (2013). Prospective, randomized assessment of transfer of training (ToT) and transfer effectiveness ratio (TER) of virtual reality simulation training for laparoscopic skill acquisition. Annals of surgery, 257, 1025-1031.

Gee, J. P. (2000). Identity as an analytic lens for research in education. Review of Research in Education, 25, 99-125.

Gee, J. P. (2001). Reading as situated language: a sociocognitive perspective. Journal of Adolescent \& Adult Literacy, 44, 714-725.

Gee, J. P. (2003). What video games have to teach us about learning and literacy. Computers in Entertainment (CIE), 1, 20-20.

Gee, J. P. (2008). Video games and embodiment. Games and Culture, 3, 253 - 263.

Gee, J. P. (2011). An introduction to discourse analysis: Theory and method. New York: NY: Routledge.

Grossman, P., Hammerness, K., \& McDonald, M. (2009). Redefining teaching, re-imagining teacher education. Teachers and Teaching: Theory and Practice, 15, 273-289.

Guba, E. G., \& Lincoln, Y. S. (1994). Competing paradigms in qualitative research. In N. K. Denzin \& Y. S. Lincoln (Eds.), Handbook of qualitative research (pp. 105-117). Thousand Oaks, CA: Sage.

Harmon, S. W. (2011). Virtual worlds as a trigger for transformative learning. Educational Technology, 51(2), 28-32. 
Hew, K. F., \& Cheung, W. S. (2010). Use of three-dimensional (3-D) immersive virtual worlds in K-12 and higher education settings: A review of the research. British Journal of Educational Technology, 41, 33-55.

Hmelo-Silver, C. E., Duncan, R. G., \& Chinn, A. C. (2007). Scaffolding and achievement in problem-based and inquiry learning: a response to Kirschner, Sweller, and Clark (2006). Educational Psychologist, 42, 99-107.

Honey, M., Connor, K., Veltman, M., Bodily, D., \& Diener, S. (2012). Teaching with Second Life: Hemorrhage management as an example of a process for developing simulations for multiuser virtual environments. Clinical Simulation in Nursing, 8(3), e79-e85.

Jelfs, A., \& Whitelock, D. (2000). The notion of presence in virtual learning environments: what makes the environment "real". British Journal of Educational Technology, 31, $145-152$.

Kinsella, E. A. (2007). Embodied reflection and the epistemology of reflective practice. Journal of Philosophy of Education, 41, 395-409.

Korthagen, F. A., \& Kessels, J. P. (1999). Linking theory and practice: Changing the pedagogy of teacher education. Educational Researcher, 28(4), 4-17.

Lave, J., \& Wenger, E. (1991). Situated learning: Legitimate peripheral participation. Cambridge, UK: Cambridge University Press.

Lemke, J. L. (2003). Identity, development, and desire: critical questions. Retrieved April 15, 2013, from http://wwwpersonal.umich.edu/ jaylemke/papers/Identity/identity_aera_2003.htm

Luehmann, A. L. (2007). Identity development as a lens to science teacher preparation. Science Education, 91, 822-839. 
Marcia, J. E. (1966). Development and validation of ego-identity status. Journal of personality and social psychology, 3, 551-558.

Merriam, S. B. (2009). Qualitative research: A guide to design and implementation. San Fransisco, CA: Jossey-Bass.

Muir, T., Allen, J. M., Rayner, C. S., \& Cleland, B. (2013). Preparing pre-service teachers for classroom practice in a virtual world: A pilot study using Second Life. Journal of Interactive Media in Education. Retrieved from http://jime.open.ac.uk/jime/article/viewArticle/2013-03/html

Peña, J., McGlone, M. S., \& Sanchez, J. (2012). The Cowl Makes the Monk: How Avatar Appearance and Role Labels Affect Cognition in Virtual Worlds. Journal of Virtual Worlds Research, 5(3), 1-18.

Peterson, M. (2011). Towards a research agenda for the use of three-dimensional virtual worlds in language learning. Calico Journal, 29, 67-80.

Puvirajah, A., Verma, G., \& Webb, H. (2012). Examining the mediation of power in a collaborative community: Engaging in informal science as authentic practice. Cultural Studies of Science Education, 7, 375-408.

Schneider, R. (2008). Mentoring new mentors: Learning to mentor preservice science teachers. Journal of Science Teacher Education, 19, 113-116.

Schon, D. A. (1987). Educating the reflective practitioner. San Francisco: Jossey-Bass.

Shaffer, D. W. (2006). How computer games help children learn. New York, NY: Palgrave Macmillan.

Stickgold, R. (2011). The role of REM sleep in memory consolidation, enhancement, and integration. In B. Mallick, S. R. Pandi-Perumal, R. McCarley \& A. Morrison (Eds.), 
Rapid Eye Movement Sleep: Regulation and Function (pp. 328). Cambridge, UK:

Cambridge University Press.

Squire, K. (2006). From content to context: videogames as designed experience. Educational Researcher, 35(8), 19-29.

Taylor, T. L. (2002). Living digitally: Embodiment in virtual worlds. In R. Schroeder (Ed.), The social life of avatars: presence and interaction in shared virtual environments. London: Springer-Verlag.

Thomas, D., \& Brown, J. (2009). Why virtual worlds can matter. International Journal of Media and Learning, 1, 37-49.

Turkle, S. (1995). Life on the screen: Identity in the age of the internet. New York, NY: Touchstone.

Waterman, A. S., Schwartz, S. J., Hardy, S. A., Kim, S. Y., Lee, R. M., Armenta, B. E., ... \& Agocha, V. B. (2013). Good Choices, Poor Choices Relationship Between the Quality of Identity Commitments and Psychosocial Functioning. Emerging Adulthood, 1, 163174.

Wilson, M. (2002). Six views of embodied cognition. Psychonomic Bulletin \& Review, 9, 625-

Yin, R. K. (2009). Case study research: design and methods. Thousand Oaks, CA: Sage. Zweigenhaft, R. L. (1976). Personal space in the faculty office: Desk placement and the student-faculty interaction. Journal of Applied Psychology, 61, 529-532. 
Appendix

\section{Ms. Smith’s Post Conference Written Reflection}

Incident \#1: My Ooops and Oh Moment Where - Begins and ends from 0:54 - 2:40

\section{What}

This was the moment in which the parent informed me that she was concerned about her daughter's failing grades in my class. The parent informs me that their daughter Suzanne is a good student. The parent informs me that Suzanne has a study group with whom she devotes two hours with studying. The parent also informed me, the teacher, he has a stay at home wife who makes sure that their daughter studies. I then go on to say that I have documentation of her steadily failing grades, and give the specific score of her last grade, which was 60 . She scored well below the class average of $80 \%$.

\section{Emotions and Why}

Teacher's Perspective: When I "experienced" the event, I felt that [I] did not dig deeper into the issue. I sort of felt the parent was almost blaming me for her child's failure. And I felt that I was being a bit defensive, trying to save my reputation as a teacher. I also did not want to be intrusive in the parents' private life. I could've asked, "Well if Suzanne is a good student and did not have failing grades in the past and she studies for two hours, then maybe she is going through some stress at home? Or has some other problems she is going through." I did not want to intrude and felt vey hesitant into asking that kind of questions.

Parent's Perspective: As a parent I almost felt defensive when the teacher was asking do I see if Suzanne studies at home and even if she studies at all. I felt frustrated because Suzanne is such a good student and studies with her group, yet is failing in class. I felt that maybe the teacher's tests are too hard. Its also frustrating and sad to see your daughter try so hard still failing.

\section{Cultural Relevance}

As an educator, I was able to find an appropriate solution to helping Suzanne by offering to help her after school to find out exactly where she needs help by giving her that one-on-one. But I was not able to exactly find the root of Suzanne's problem. Instead of identifying the roof [sic] of Suzanne's failing grades, I went right to a solution.

\section{Position}

As an educator, I believe that a teacher and parents should have a close relationship. It's important to not only talk to parents about their child's bad behavior or grades, but it is also important to communicate with them a child's progress and praise their child's good works. As the teacher, I identified in this incident that I [k]now that Suzanne is a good students and I am also concerned for her. This makes the parents and teacher a team, when such concern is expressed, and therefore the relationship is more conducive for a positive outcome.

\section{Actions}

As an educator, I will try to find the root of the student's problem. I would try not to be afraid of asking some more personal questions, as long as the focus is always in the student and the parents or anybody else. 
Incident \#2 The Solutions

Where - Begins and ends from 4:24-5:50

\section{What}

In this incident, I, the teacher, suggested that I keep Suzanne after school to see exactly how I can help her by giving her that individual attention. The parent agreed to this. I also told the parent that I would stay in touch with then $[s i c]$ as I tutor Suzanne after school to give them Suzanne's progress. I promise to tell the parents where exactly Suzanne's weaknesses might be and help her there.

\section{Emotions and Why}

Teacher's Perspective: During this incident, I felt I was being hasty in perhaps not finding the root of the Suzanne's failing grades. But at the same time, I felt good that I could offer her any kind of help, so that I may find out the root of the problem as I continue to teacher [sic] her oneon-one and get to also know her better. So I felt a little relieved that I may yet reach her.

Parent's Perspective: I felt happy that the teacher was willing to take her own time off after class to help Suzanne. It shows me that she cares and does want best for Suzanne. Overall, I felt satisfied with the solution. Individual attention is good for Suzanne.

\section{Cultural Relevance}

As an educator, I was concerned about my student and therefore, did not want to put the blame on either Suzanne or her parents. I was happy to find a solution agreeable with the parent. The problem with Suzanne could be that despite all her studying, she might not be doing effective studying, and I can find this out by working individually with her.

\section{Position}

As an educator, I believe, again in a strong parent-teacher relationship. I also believe that parents should be very much involved in their child's education. Through this incident, the parent and teacher were able to keep a good relation especially when it was suggested to give weekly progress of Suzanne's work. As an educator, I'm ecstatic that the child's parents are $100 \%$ on board and want to help any way possible.

\section{Actions}

As an educator, I will make sure that the student is also there with the parents. I believe that sometimes it's good just to talk to the parents, but at other times, it is also good to include the student so that they can include their perspective and then perhaps we would have a better understanding and a better solution as to how the student could be helped. Perhaps my solution was not best for the student, but if the student were present, we could've figured out the best solution together. 